\title{
Lipid Metabolic Pathways Confer the Immunosuppressive Function of Myeloid-Derived Suppressor Cells in Tumor
}

\section{OPEN ACCESS}

Edited by:

Olivera J. Finn,

University of Pittsburgh, United States

Reviewed by:

Limin Zheng,

Sun Yat-sen University, China

Maria Dulfary Sanchez-Pino,

Louisiana State University,

United States

*Correspondence:

Xiaochun Wan

xc.wan@siat.ac.cn

these authors have contributed equally to this work

Specialty section:

This article was submitted to

Cancer Immunity and Immunotherapy,

a section of the journal

Frontiers in Immunology

Received: 20 February 2019 Accepted: 03 June 2019

Published: 19 June 2019

Citation:

Yan D, Adeshakin AO, Xu M, Afolabi LO, Zhang G, Chen YH and

Wan X (2019) Lipid Metabolic

Pathways Confer the Immunosuppressive Function of

Myeloid-Derived Suppressor Cells in

Tumor. Front. Immunol. 10:1399.

doi: 10.3389/fimmu.2019.01399

\section{Dehong Yan ${ }^{1 \dagger}$, Adeleye O. Adeshakin ${ }^{1,2+}$, Meichen Xu ${ }^{1,3}$, Lukman O. Afolabi ${ }^{1,2}$, Guizhong Zhang ${ }^{1}$, Youhai H. Chen ${ }^{4}$ and Xiaochun Wan ${ }^{1,2 *}$}

${ }^{1}$ Shenzhen Laboratory for Human Antibody Engineering, Center for Antibody Drug Development, Shenzhen Institute of Advanced Technology, Chinese Academy of Sciences, Shenzhen, China, ${ }^{2}$ University of Chinese Academy of Sciences, Beijing, China, ${ }^{3}$ School of Life Science and Technology, Jinan University, Guangzhou, China, ${ }^{4}$ Department of Pathology and Laboratory Medicine, Perelman School of Medicine, University of Pennsylvania, Philadelphia, PA, United States

Myeloid-derived suppressor cells (MDSCs) play crucial roles in tumorigenesis and their inhibition is critical for successful cancer immunotherapy. MDSCs undergo metabolic reprogramming from glycolysis to fatty acid oxidation (FAO) and oxidative phosphorylation led by lipid accumulation in tumor. Increased exogenous fatty acid uptake by tumor MDSCs enhance their immunosuppressive activity on T-cells thus promoting tumor progression. Tumor-infiltrating MDSCs in mice may prefer FAO over glycolysis as a primary source of energy while treatment with FAO inhibitors improved anti-tumor immunity. This review highlights the immunosuppressive functions of lipid metabolism and its signaling pathways on MDSCs in the tumor microenvironment. The manipulation of these pathways in MDSCs is relevant to understand the tumor microenvironment therefore, could provide novel therapeutic approaches to enhance cancer immunotherapy.

Keywords: MDSCs, lipid metabolism, FAO-OXPHOS, immunosuppressive, cancer immunotherapy

\section{INTRODUCTION}

Myeloid-derived suppressor cells (MDSCs) are pathologically activated cells displaying an exceptional immunosuppressive ability $(1,2)$. They rapidly expand in cancer, trauma, infectious, autoimmune, and graft vs. host disease (3-8). MDSCs are phenotypically similar to monocytes and neutrophils, thus are further divided into two subsets; monocytic MDSCs (M-MDSCs) and polymorphonuclear MDSCs (PMN-MDSCs) respectively $(9,10)$. Generally, the cell surface markers for MDSCs include Gr1 and CD11b in mice $(11,12)$. The M-MDSCs are characterized by

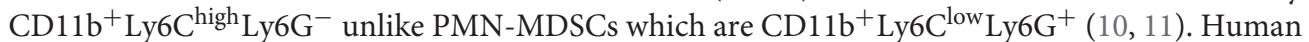
M-MDSCs on the other hand, are $\mathrm{CD} 33^{\text {high }} \mathrm{CD} 14^{+} \mathrm{CD} 15^{+} / \mathrm{CD} 6 \mathrm{~b}^{-} \mathrm{HLA}-\mathrm{DR}{ }^{-/ \text {low }}$, whereas PMN-MDSCs are characterized by $\mathrm{CD} 33^{\mathrm{dim}} \mathrm{CD} 14^{-} \mathrm{CD} 15^{+} / \mathrm{CD} 6 \mathrm{~b}^{+} \mathrm{HLA}-\mathrm{DR}{ }^{-}(13,14)$. More importantly, these cells potently suppress innate and adaptive immunity. Thus, are considered a promising therapeutic target in cancer immunotherapy.

Metabolic reprogramming has been reported to be a crucial factor in the alteration of MDSCs function (15-20). Lipids which maintain cell membrane integrity, homeostasis, signaling, and healthy performance have been implicated to modulate the function of MDSCs (21-23). Recently, uncontrolled lipid accumulation was found to be higher in MDSCs from cancer patients and 
mice with an established tumor compared with tumor-free counterparts (24-26). This increased the immunosuppressive activity in the hyperlipidemic tumor-bearing mice and impaired T-cell activation $(24,25,27)$. In this review, we discuss the roles of lipid in modulating MDSCs function and its related metabolic pathways. Further understanding of the biochemical pathways involved in lipid manipulation of MDSCs is pertinent to understand the tumor microenvironment and improve chemoand immuno-therapies.

\section{AN OVERVIEW OF LIPID METABOLISM IN MDSCS}

Acetyl CoA, a major intermediate in several biochemical processes plays a pivotal role in lipid metabolism. It is the primary building blocks for biosynthesis of fatty acid, cholesterol, and the end product of fatty acid oxidation (FAO). Lipid catabolism involves the oxidation of long-chain fatty acids, which takes place in the mitochondrial via the transportation of lipids from the cytosol by the carnitine palmitoyltransferase system. Carnitine palmitoyltransferase 1 (CPT1) catalyzes the rate-limiting step in FAO. During fatty acid oxidation, the continuous elimination of 2 -carbon units from the $\beta$-position of fatty acyl-CoA molecule produces acetyl CoA which sustains oxidative phosphorylation (OXPHOS) and tricarboxylic acid cycle (TCA) in the cell (28, 29). In contrast to FAO, synthesis of fatty acid occurs in the cytosol; commencing with the carboxylation of acetyl CoA to malonyl CoA in an ATP-dependent manner catalyzed by acetyl CoA carboxylase 1 (ACC1), the reaction rate determining enzyme (Figure 1). This is followed by the condensation of another molecule of acetyl CoA with the malonyl CoA to produce saturated long chain fatty acids in a process catalyzed by fatty acid synthase (FASN). These steps lead to the formation of other complex lipids like phospholipids, cholesterol esters, and triglycerides.

\section{ENERGY METABOLIC PATHWAYS OF MDSCS}

It is important to note that nearly all major biomolecules (carbohydrates, proteins, and lipids) are converted to a common intermediate in the form of acetyl CoA. Acetyl CoA can be further oxidized to $\mathrm{CO}_{2}$ or take part in some other biosynthetic pathways as required by the cells. Production of adenosine triphosphate (ATP) to enhance cellular functions, survival, and synthesis of intermediates allowing for cellular growth and proliferation by immune cells rely on various energy metabolic pathways $(30,31)$. Interconnection of metabolic network (glycolysis, the TCA cycle, and OXPHOS) plays a crucial role in fulfilling these energy needs (Figure 1). Glycolysis occurs in the cytosol while the TCA cycle and OXPHOS are restricted to the mitochondria. Glycolysis commences with glucose uptake from the extracellular environment via GLUT; glucose is then phosphorylated to glucose-6- phosphate (G6P) by hexokinases. G6P is further processed to pyruvate via multiple enzymecatalyzed reactions during which it reduces $\mathrm{NAD}^{+}$to $\mathrm{NADH}$ to yield 2 molecules of ATP. Under normoxia, glycolysisderived pyruvate is converted into acetyl-CoA in a reaction regulated by pyruvate dehydrogenase $(\mathrm{PDH})$ complex. This acetyl $\mathrm{CoA}$ condenses with oxaloacetate to form citrate in a reaction catalyzed by citrate synthase in the TCA cycle. This cycle produces $\mathrm{NADH}$ and $\mathrm{FADH} 2$ and transfers electrons generated through the electron transport chain (ETC) to fuel OXPHOS to yield 30-36 molecules of ATP per molecule of glucose. Cells can also use fatty acid through FAO, which yields acetyl-CoA to sustain the TCA cycle and OXPHOS; this can facilitate the generation of substantial amounts of ATP (over a 100 ATP molecules per molecule of palmitate). Most importantly, cells to a varying extent can select their preferred metabolic pathways among several available intermediates to produce ATP. In the immune cells, nutrient, and oxygen availability which can be controlled by growth factors and cytokines, as well as important receptor signaling events, regulate the metabolic fate of these cells.

Certain key enzymes derived from MDSCs are important to their suppressive role, these enzymes deplete the essential amino acids required for $\mathrm{T}$-cell function and proliferation (32). Increased arginase 1 (ARG1) expression in MDSCs depletes L-arginine needed for T-cell functions (33). Also, MDSCs accumulation deplete L-cysteine levels via its sequestration and consumption (34). The depletion of these amino acids results in downregulation of $\zeta$-chain in the $\mathrm{T}$ cell receptor (TCR) thus inhibiting proliferation of antigen-specific T-cells. Similarly, MDSCs express the inducible enzyme Indoleamine 2, 3-dioxygenase (IDO), which catalyzes tryptophan metabolism through the kynurenine pathway $(35,36)$. Thus, IDO expression leads to tryptophan deprivation and induces regulatory T-cells (Tregs) expansion which represses T-cells $(37,38)$. While the pivotal role of nitrogen metabolism in mediating the immunosuppressive function of MDSCs on T-cells in tumors is well-established (32), little is known about other metabolic pathways in these cells. Carbon metabolism (glycolysis, pentose phosphate pathway (PPP), TCA, FAO pathways) and its crosstalk with nitrogen metabolism during MDSCs maturation in tumors need to be expounded.

FAO and glycolysis are crucial pathways in tumor growth (39), however, it is not known whether MDSCs prefer FAO over glycolysis. It was previously reported that tumor-infiltrating MDSCs (M-MDSCs and PMN-MDSCs) in comparison with peripheral MDSCs and murine myeloid cells prefer FAO as their energy sources (27). This was deduced from the observed elevated mitochondrial mass, increased oxygen consumption rate (OCR) and upregulation of crucial FAO regulatory enzymes [acyl-CoA dehydrogenase (ACADM), CPT1, 3-hydroxyacylCoA dehydrogenase (HADHA), and peroxisome proliferatoractivated receptor gamma coactivator 1-beta (PGC1 $\beta)$ ] in PMNMDSCs. The study revealed a correlation between expression of FAO genes (such as CPT1 and HADHA) and fatty acid uptake in patient-derived tumor-infiltrating $\operatorname{MDSCs}(22,27)$. In the study, both extracellular acidification rate (ECAR) and OCR were elevated, indicating an overall metabolic alteration. Although the ratio of OCR/ECAR was increased, suggesting that FAO may be 


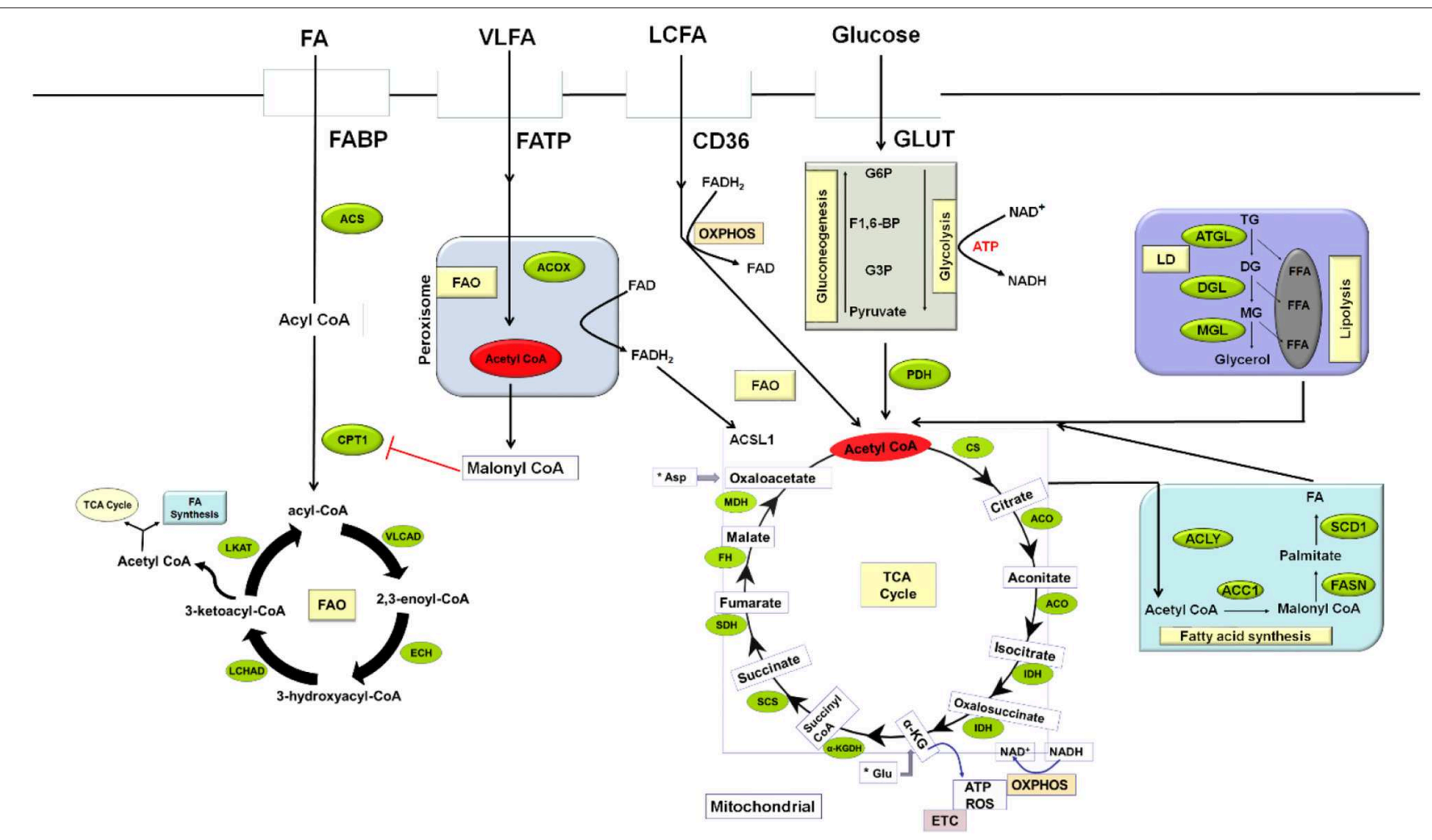

FIGURE 1 | An overview of MDSCs Lipid Metabolism in a tumor environment. Lipid metabolism in MDSCs can undergo two processes: fatty-acid synthesis and fatty-acid $\beta$-oxidation. Fatty acid synthesis takes place in the cytosol while $\beta$-oxidation occurs in the mitochondrial. Several metabolic networks regulate the activation and survival of MDSCs to enhance tumor proliferation. Glycolysis, the breakdown of glucose to pyruvate with the concomitant release of ATP taking place in the cytosol is the major source of energy to most cells. In the mitochondrial, PDH converts pyruvate to acetyl CoA, the central dogma of metabolism which has several metabolic fates, including TCA cycle, oxidative phosphorylation, and fatty acid biosynthesis. ACC1, Acetyl CoA carboxylase; ACLY, ATP citrate lyase; ACO, Aconitase; ACOX, Acyl CoA oxidase; ACS, Acyl CoA synthase; ACSL1, long-chain acyl-CoA synthetase isoform 1; Asp, Aspartate; ATGL, Adipose triglyceride lipase; ATP, Adenosine triphosphate; CD36, Cluster of differentiation 36; CPT, Carnitine palmitoyltransferase 1; DG, Diglyceride; DGL, Diglyceride lipase; ECH, 2, 3-enoyl-CoA hydratase; ETC -Electron transport chain; F1,6-BP, Fructose-1,6-bisphosphate; FA, Fatty acid; FABP, Fatty acid-binding protein; FAD, Flavin adenine dinucleotide; FADH2, Reduced FAD; OXPHOS, Oxidative phosphorylation; FAO, Fatty acid oxidation; FASN, Fatty acid synthase; FATP, Fatty acid transport protein; FFA, Free fatty acid; FH, Fumarate hydratase; G3P, Glyceraldehyde-3-phosphate; Glu, Glutamate; GLUT, Glucose transporter; GP6, Glucose-6-phosphate; IDH, Isocitrate dehydrogenase; LCHAD, Long-chain 3-hydroxyacyl-CoA dehydrogenase; LD, Lipid droplet; LKAT, long chain 3-ketoacyl-CoA thiolase; MDH, Malate dehydrogenase; MG, Monoglyceride; MGL, Monoglyceride lipase; NAD, Nicotinamide adenine dinucleotide; PDH, Pyruvate dehydrogenase; ROS, Reactive Oxygen species; SCD1, Stearoyl-CoA desaturase 1; SCS, Succinyl CoA synthase; SDH, Succinate dehydrogenase; TCA, Tricarboxylic acid; TG, Triglyceride; VLCAD, Very-long-chain acyl-CoA dehydrogenase; VLFA, Very long chain fatty acid; LCFA, Long chain fatty acid; $\alpha-K G$, Alpha-ketoglutarate; $\alpha-K G D H$, Alpha ketoglutarate dehydrogenase.

preferred to glycolysis in tumor-infiltrating MDSCs from Lewis lung carcinoma.

In addition, Jian et al., recently reported that ECAR and glycolytic enzymes are upregulated in total MDSCs. Whereas, PMN-MDSCs were observed to utilize both glycolysis and oxidative phosphorylation to produce energy for its suppressive role due to the elevated metabolic state of the tumor-bearing host (40). Inhibition of two key enzymes in glycolysis: hexokinase (HK) and glyceraldehyde-3-phosphate dehydrogenase (GAPDH) by 2-deoxyglucose (2-DG) and sodium iodoacetate (IA), respectively, reduced MDSCs expansion, leading to a delay in tumor progression via induction of ROS-mediated apoptosis of MDSCs (40).

Another study reported that latent membrane protein 1 (LMP1) associated with Epstein-Barr virus mediates glycolysis by upregulating GLUT1 in tumor (41). This promotes the induction of GM-CSF, IL-6, and IL-1 $\beta$ production through COX-2 and NLRP3 inflammasome signaling pathways to enhance MDSCs differentiation and expansion, thereby promoting nasopharyngeal carcinoma (NPC) progression (41). However, a more recent study reported that EBV-encoded LMP1 induces de novo lipogenesis and lipid droplets formation through the activation of sterol regulatory element-binding protein 1 (SREBP1) which promotes progression of NPC (42). This suggests that LMP1 could also mediate other metabolic pathways such as lipogenesis (previously reported) or FAO to regulate MDSCs alteration in NPC progression. Therefore, a comprehensive study on the role of LMP1 expression in regulating immune cells (especially MDSC) in tumor state could help broaden understanding of the most upregulated pathway in MDSCs. 
A recent study reported the correlation between MDSCs and glycolysis in human triple negative breast cancer (TNBC) and observed that restriction of glucose metabolism inhibits G-CSF and GM-CSF expression (43). This resulted in reduced MDSCs number while conferring tumor immunity by enhancing $\mathrm{T}$-cell function. MDSCs are able to utilize anaerobic glycolysis when oxygen supply is limited to enhance their immunosuppressive role in the tumor microenvironment (44). This was observed by the upregulation of lactate dehydrogenase A (LDHA) (43), an enzyme involved in the reversible reaction of pyruvate to lactic acid. This could be an indicator of highly proliferative and energy demanding cell for the production of $\mathrm{NAD}^{+}$in subsequent ATP generation when oxidative phosphorylation is restricted due to insufficient oxygen availability. Inhibition of LDHA in a murine pancreatic cancer model decreased MDSCs frequency in the spleen and enhanced cytolytic activity of natural killer (NK) cells (44). Extrinsic lactic acid also increased the proportion of MDSCs derived from bone marrow (BM) cultured cells in the presence of GM-CSF and IL-6. Furthermore, MDSCs undergoing anaerobic glycolysis partly oxidize L-glutamine to provide a favorable condition for tumor growth (45). Although anaerobic glycolysis occurs 100 times faster than oxidative phosphorylation, it is less efficient and only helps in fulfilling a short-term energy requirement when oxygen supply is low (46).

Based on the diversity and dynamic attributes of the tumor milieu across various cancers as well as the stage of progression of same cancer, it is possible that the process of nutrient metabolism in immune cells might also differ across these conditions (39, 47). Recent studies have reported that the switch between glycolysis and oxidative phosphorylation in tumor-associated macrophages (TAM) is dependent on the stages of cancer development $(48,49)$. In relation to TAM, MDSCs also exhibit a certain degree of plasticity and may adopt a typically activated (M1) or alternatively activated (M2) phenotype, with antitumor or tumor-promoting roles, respectively (50). Therefore, the alterations of MDSCs differentiation, maturation and function may rely on overall central carbon metabolism and upregulation of cellular bioenergetics fluxes (45).

So far, the metabolic preference of MDSCs in tumor microenvironments is not fully known and requires more robust investigations. However, current evidence suggests that it may involve global regulation of metabolic flux.

\section{OXIDIZED LIPIDS REGULATE MDSCS FUNCTION IN THE TUMOR MICROENVIRONMENT}

Utilization of oxidized lipid as an energy source is crucial to the immunosuppressive roles of MDSCs in the tumor microenvironment (24). Gabrilovich et al. demonstrated that accumulation of oxidized lipids in tumor-infiltrating $\mathrm{CD} 11 \mathrm{c}^{+}$ DCs blocks antigen presentation and their orientation on major histocompatibility complex (MHC) class II $(51,52)$. This, in turn, blocks antigen-mediated cross-presentation and inhibits $\mathrm{T}$ cell stimulation. They also showed that targeting ACC1 with 5- (tetradecycloxy)-2-furoic acid (TOFA), reverses the effects of lipids, suggesting that the fatty acid biosynthesis pathway is involved in this process (Figure 2) (51).

In line with other myeloid cells, substantial lipid accumulation was observed in tumor-derived MDSCs $(24,53)$. MDSCs with lipid overload demonstrated greater immunosuppressive effect on $\mathrm{CD}^{+}{ }^{+} \mathrm{T}$ cells, compared to MDSCs with normal lipid content. Lipid accumulation in tumor-derived MDSCs can be linked to an increase in fatty acid uptake. This is supported by the study of Cao et al., which revealed an increased expression of fatty acid transport protein 4 (FATP4) in murine tumor-derived MDSCs (53). Most of the lipids detected in the MDSCs of tumor-bearing mice and cancer patients were found to be oxidized (Figure 2), possibly resulting from the oxidative activities of reactive oxygen species (ROS) and myeloperoxidase (MPO) $(24,54)$. Inhibition of ROS and MPO in these cells almost completely expunged the oxidation of lipids and resulted in MDSCs with a diminished immunosuppressive activity (24).

A recent study identified the upregulation of FATP2 on PMN-MDSC as a critical regulator of their immunosuppressive function (26). FATP2 promotes the accumulation of arachidonic acid leading to prostaglandin E2 (PGE2) synthesis in PMNMDSCs thereby boosting their immunosuppressive activities. Thus, the pharmacological inhibition of FATP2 could serve as a novel and targeted therapeutic strategy to block the

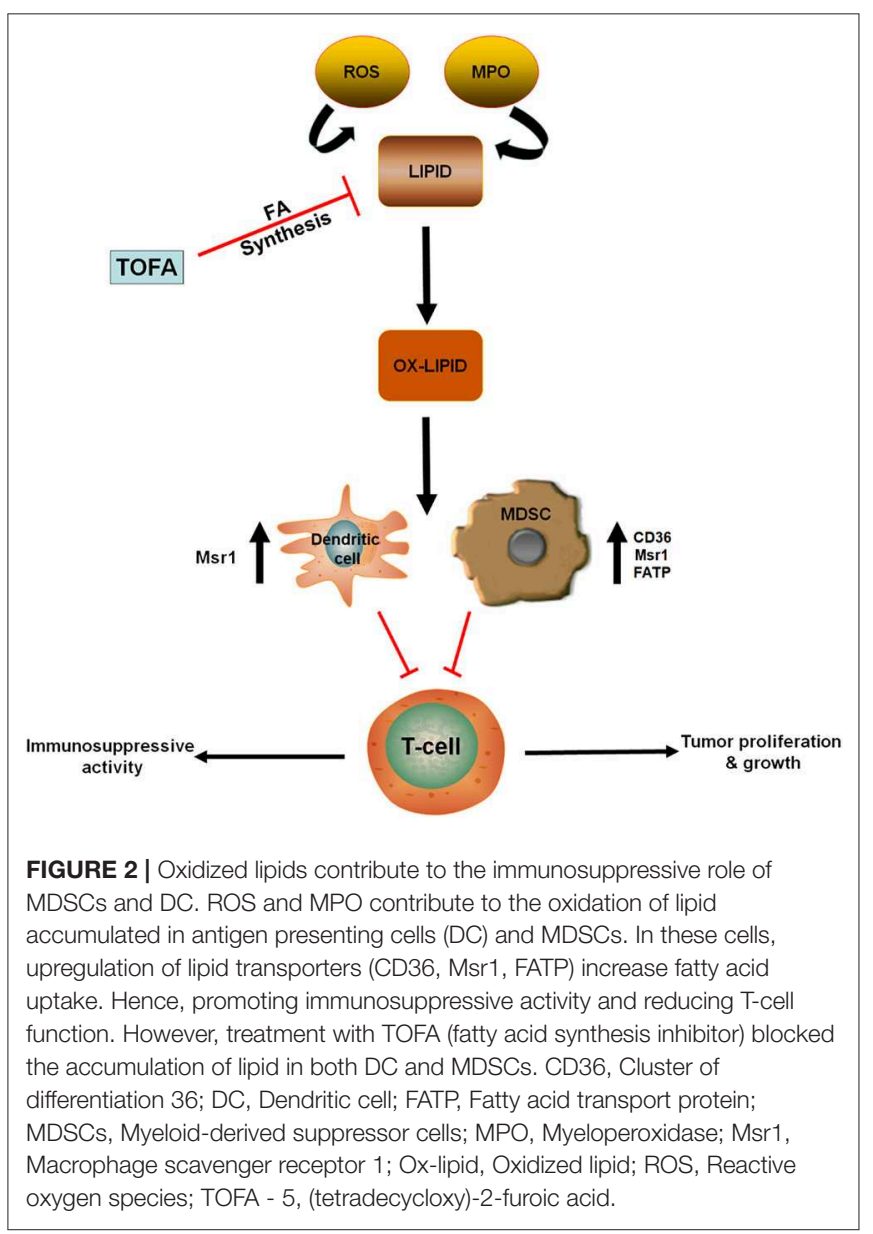


immunosuppressive activity of PMN-MDSCs. Collectively, these studies suggest the critical role of oxidized lipids in regulating myeloid cells function and specifically in MDSC as a potential therapeutic target in cancer.

\section{EXOGENOUS FATTY ACID UPTAKE ENHANCES SUPPRESSIVE ACTIVITY IN MDSCS}

MDSCs take up fatty acids from the tumor microenvironment and utilize them via several pathways. Our group previously reported that polyunsaturated fatty acids (PUFAs) impaired myeloid cell differentiation in bone marrow from tumorbearing mice thus promoting the accumulation and functional activity of MDSCs (55). The study further demonstrated that dietary intake of linoleic acid (LA) and alpha-linolenic acid (ALA) promoted tumor growth in agreement with the observation by another group (56). It was recently discovered that culturing MSC-2, a myeloid suppressor cell line in the presence of long chain unsaturated fatty acids, oleate and linoleate increased lipid droplet accumulation which in-turn suppressed T-cell activity (57). However, T-cell activation remained unaffected in MSC-2 cells cultured in the presence of stearate, a saturated fatty acid that also accumulated lipid droplets. Removal of oleate from the culture medium triggered the mobilization of lipid droplets in this cell-line, thereby diminishing its immunosuppressive activity. Furthermore, it was observed that inhibiting diacylglycerol acyltransferases (DGAT) abolishes oleate-induced lipid droplet formation and impaired the immunosuppressive activity of MSC-2 (57). In addition, another group of researchers reported that MDSCs treated with linoleic acid demonstrated a stronger inhibitory effect on T-cell compared to those treated with palmitic acid which is a saturated fatty acid (53). In summary, unsaturated fatty acids which are known to be more susceptible to oxidation, contribute to the suppressive ability of MDSCs during cancer via upregulation of lipid metabolic gene such as DGAT.

\section{SIGNALING PATHWAYS INVOLVED IN LIPID METABOLISM OF MDSCS}

Recent findings suggest a relationship between oxidative phosphorylation initiated by lipid metabolism and its contribution to immunosuppressive myeloid cells. However, the underlying molecular mechanisms associated with FAO in subpopulations of tumor-infiltrating MDSCs is yet to be fully elucidated $(54,58)$. The role of kinases like AMPK and $\mathrm{PI} 3 \mathrm{~K}$, transcription factors such as STATs, enzymes involved in FAO as well as several receptors including Peroxisome proliferator-activator receptors (PPARs), among others on immune cells, including MDSC, has been described in different in vitro and in vivo models. For example, pharmacological inhibition of STAT3 and STAT5 (activated by tumor-derived cytokines) decreased lipid accumulation, mitochondrial metabolism, and immunosuppressive function in MDSCs in an in vitro study (25). Increased expression of crucial genes encoding enzymes in FAO is linked to the suppressive role of tumor MDSCs which was abolished by FAO inhibitors (27). More detailed description of those critical components of the signaling pathways involved in the cellular lipid metabolism is described below.

\section{LXR}

Liver $\mathrm{X}$ receptors comprise two isoforms, $\operatorname{LXR} \alpha$ and $\operatorname{LXR} \beta$ which are encoded by Nr1h3 and Nr1h2, respectively. Both isoforms are members of the nuclear hormone receptor family that modulate several transcriptional factors. LXR acts as a critical regulator of lipid homeostasis (Figure 3) by driving the expression of key genes involved in cholesterol, fatty acid, and glucose metabolism $(59,60)$.

Masoud et al., reported the effect of LXR activation on MDSCs expansion and their immunosuppressive activities on T-cell stimulation both in vivo and in vitro (61). RGX-104, an LXR agonist, significantly decreased the abundance of PMNMDSCs and M-MDSCs from B16F10 melanoma tumor-bearing mice. The proportion of PMN-MDSCs generated in vitro from bone marrow cells treated with LXR agonist was decreased in the presence of GM-CSF. Oral administration of RGX-104 also decreased the population of MDSCs in cancer patients. It was previously reported that cholesterol-induced LXR sumoylation blocks IL-9 expression in $\mathrm{CD}^{+} \mathrm{T}$ cells, partially by reducing the binding of NF- $\kappa B$ p65 subunit to IL-9 promoter (62). IL-9 demonstrates a critical role in the antitumor response of $\mathrm{CD} 8^{+} \mathrm{T}$ cell subset (Tc9) (62-64). Also, IL-9 expressing T-cells have been identified in humans (65) and it was reported to enhance the function and survival of human tumor-infiltrating T-cells (66). It is imperative to decipher how the accumulation of lipids or exogenous fatty acid uptake regulates LXR signaling pathways in immune cells.

LXR promotes the transcriptional activation of a secretory protein, apolipoprotein E (ApoE) (61), which mediates the cellular uptake of lipoprotein particles by binding to low-density lipoprotein receptor (LDLR) and chylomicron remnants receptor (67). ApoE interaction with these receptors activates lipid (such as cholesterol, phospholipid, and triglycerides) metabolic pathways (68). A recent study showed that ApoE regulates MDSCs survival and tumor progression; $\mathrm{ApoE}^{-/-}$mice had increased levels of $\mathrm{PMN}$ MDSCs and M-MDSCs. MDSCs from ApoE deficient mice showed reduced T-cell proliferation in vitro (61). Since ApoE plays a crucial role in lipoprotein metabolism (69), its deletion could enhance MDSCs immunosuppressive activity on T-cells via lipid accumulation. Al-Khami et al., reported the accumulation of lipid in bone-marrow derived MDSCs following extracellular uptake of low-density lipoproteins (LDL) and very low-density lipoproteins (VLDL) (25). This was observed to enhance oxidative metabolism and upregulation of ARG1 in MDSCs. Altogether, these suggest that the regulation of lipid metabolism via ApoE expression may alter MDSCs function in the tumor milieu. 


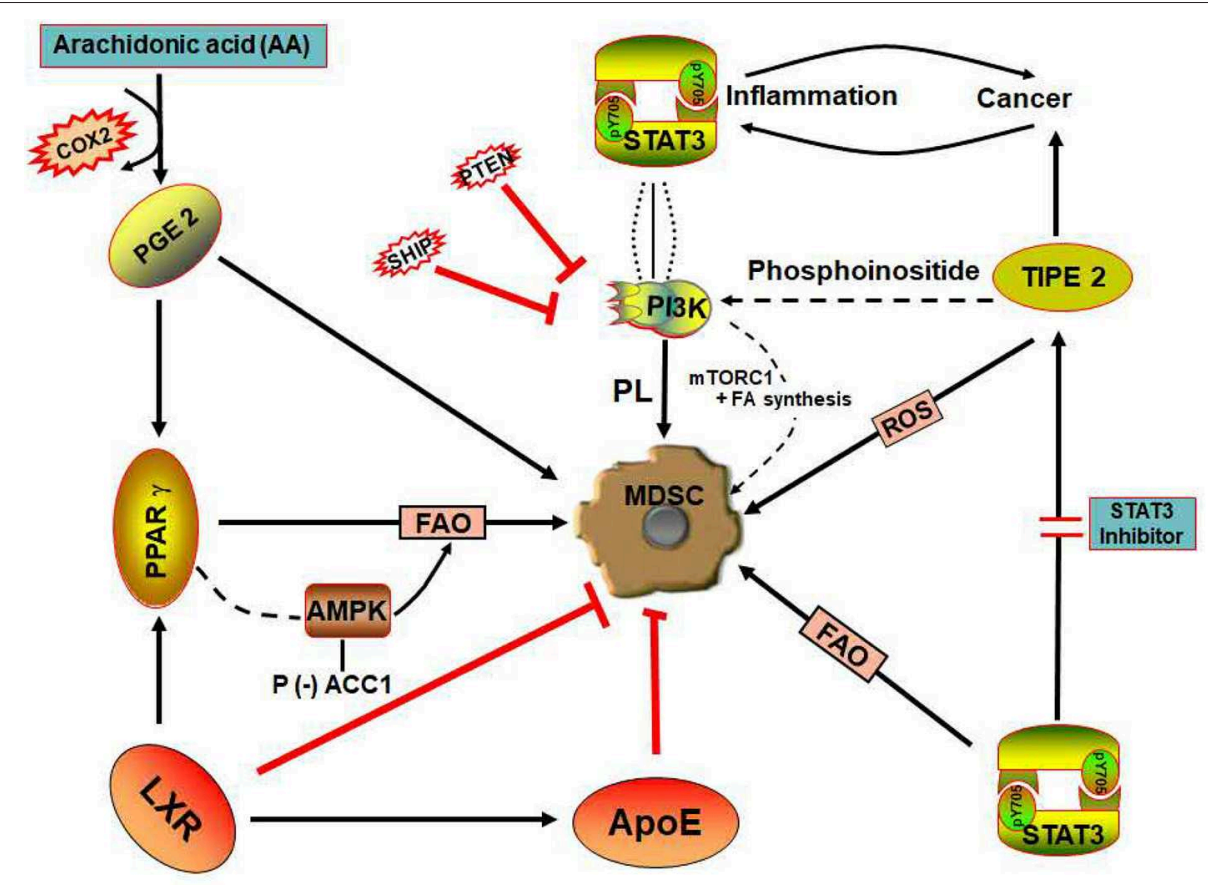

FIGURE 3 | Signaling pathways involved in lipid metabolism of MDSCs. (i) SHIP and PTEN are negative regulators of PI3K/AKT-involved in the promotion of lipid and sterol synthesis (ii) COX-2 is the enzyme which catalyzes arachidonic acid into PGE2, a pro-inflammatory lipid mediator that could result in elevated MDSCs. (iii) PPAR- $\gamma$ initiates AMPK activation, thereby promoting FAO in MDSCs to enhance its immunosuppressive ability. (iv) LXR is a nuclear hormone receptor that regulates lipid homeostasis and enhances the transcriptional activation of ApoE-involved in lipoprotein metabolism. LXR inhibits MDSCs suppressive activity on T-cells. (v) STAT3 signaling enhances FAO and also upregulates TIPE2 expression in MDSCs. (vi) TIPE2, a promoter of the immunosuppressive function of MDSCs, regulates PI3K via signaling of phosphoinositide and can be inhibited by STAT3 inhibitors. ACC1, Acetyl CoA carboxylase 1; AMPK, AMP-activated protein kinase; APOE, Apolipoprotein E; COX-2, Cycloxygenase 2; FAO, Fatty acid oxidation; LXR, Liver X receptors; MDSCs, Myeloid-derived suppressor cells; mTORC1, mammalian target of rapamycin complex 1; PGE2, Prostaglandin E2; PI3K, Phosphoinositide-3-Kinase; PL, Phospholipid; PPAR $\gamma$, Peroxisome proliferator-activator receptors gamma; PTEN, Phosphatase and tensin; ROS, Reactive oxygen species; SHIP-5-inositol phosphatase; STAT 3, Signal transducer and activator of transcription; TIPE 2, Tumor necrosis factor alpha-induced protein 8 like 2; P, Phosphorylation; +, Stimulate; -, Deactivation.

\section{PPARs}

Peroxisome proliferator-activator receptors (PPARs) are "lipid sensing" nuclear receptors activated by free fatty acid (FFA), prostaglandins, eicosanoids, or sterols (70). They are divided into three subtypes which are: $\operatorname{PPAR} \alpha, \operatorname{PPAR} \gamma$, and PPAR $\delta$. PPAR $\gamma$ and PPAR $\delta$ elicit the expression of certain FAO genes (Figure 3) and coordinate anti-inflammatory functions while PPAR $\alpha$ directly upregulates the expression of CPT1a (71), a crucial enzyme involved in mitochondrial fatty acid oxidation.

PPAR $\gamma$ plays an important role in regulating lysosomal acid lipase (LAL) activity, a key enzyme in the metabolism of neutral lipids. $\mathrm{LAL}^{-/-}$MDSCs demonstrate greater immunosuppression thereby promoting tumor cell proliferation, growth and metastasis. Activation of PPAR $\gamma$ pathway in $\mathrm{LAL}^{-/-}$ MDSCs impaired tumor growth and metastasis in vivo as well as in vitro (72). Cardiolipin, a phospholipid, promotes IL-10 expression in MDSCs from the lungs of tumor-bearing mice by activation of PPAR $\gamma$ activity $(70,73)$ but this can be inhibited by GW9662 (a specific inhibitor of PPAR $\gamma$ ) (74). However, the roles of the PPAR family in tumor biology remain unclear.
PPAR $\alpha$ was reported to mediate the transcription initiation of CPT gene in $\mathrm{CD}^{+}{ }^{+}$T-cells isolated from Jurkat cell and a murine model of non-alcoholic fatty liver disease (NAFLD, a risk factor of hepatocellular carcinoma) (75) treated with linoleic acid. PPAR $\alpha$ agonist, benzofibrate, increased the generation of mitochondrial ROS and induced apoptosis by upregulating CPT1a following treatment with LA in murine and Jurkat cell. This effect was reversed in the presence of PPAR $\alpha$ inhibitor (GW6471), illuminating the important role PPAR $\alpha$ may play in regulating CPT1 (76).

Furthermore, PPAR $\alpha$ agonist, fenofibrate, enhanced fatty acid catabolism in $\mathrm{CD}^{+} \mathrm{T}$-cell under hypoxia and low glucose condition (77) thereby activating genes encoding proteins (such as PPAR $\alpha$ and CPT1a) involved in lipid metabolism and TCA cycle. Vaccinated animals to elicit melanoma-specific CD8 ${ }^{+}$TILs response and treated with fenofibrate significantly delayed tumor progression, confirming that enhanced fatty acid catabolism improves $\mathrm{CD}^{+}$TILs functions. In PPAR $\alpha \mathrm{KO}$ mice, $\mathrm{CD} 8^{+}$cells cultured in glucose-deprived media exhibited a reduction in the transcript for fatty acid metabolism and lower functionality in comparison with the wild-type cells (77). This study suggests fatty acid catabolism is essential for CD8 ${ }^{+}$TILs functions when access 
to glucose is limited. Therefore, targeting PPARs pathways could be another promising option in manipulating lipid content in MDSCs for successful cancer therapy.

\section{AMPK}

AMP-activated protein kinase (AMPK) is a potential mediator of lipid metabolism regulating cellular homeostasis in MDSCs (45). Activation of PGC1 $\beta /$ PPAR $\gamma$ axis induces AMPK signaling, demonstrating a crucial role in mitochondrial biogenesis; thereby activating the expression of genes encoding proteins involved in FAO (15). More so, AMPK regulates the phosphorylation and deactivation of ACC1, the key enzyme involved in the regulation of fatty acid synthesis (78) (Figure 3).

MDSC-mediated AMPK phosphorylation could increase survival of multiple myeloma cells. Treatment with compound C (AMPK inhibitor) in the presence or absence of MDSCs decreased AMPK phosphorylation and induced apoptosis of multiple myeloma cells (79). Oxidative stress and upregulation of HIF- $1 \alpha$ were reported as triggers of AMPK activation in osteosarcoma cells $(80,81)$. Since MDSCs from tumor-bearing mice and cancer patients demonstrate a high amount of intracellular ROS (40, 82-84), it is possible that accumulated ROS may enhance AMPK activity. In addition, cytokines such as IL-10 and TGF- $\beta$ are elevated in MDSCs $(85,86)$ and may also induce AMPK phosphorylation.

Although the role of AMPK activation in cancer is widely studied and considered as a tumor suppressor [reviewed in (87)], its activity in modulating MDSCs function remains unclear. There have been conflicting reports on the exact role of AMPK in modulating MDSCs activity. It was recently demonstrated that pharmacological targeting of AMPK abrogates MDSCs function in tumors by repressing the expression of iNOS, arginase, and promoting T-cell proliferation $(88,89)$. Another report suggested that AMPK signaling enhances MDSCs immunosuppressive activity in doxorubicin-resistant tumors via upregulation of miR10a expression (90). However, inhibition of miR-10a abrogated the elevated $\mathrm{CD}_{11} \mathrm{~b}^{+} \mathrm{Gr} 1^{+}$MDSCs frequency and also M2 signature genes such as ARG1, TGF- $\beta$, and MMP9. Hence, there is a need for more comprehensive studies to elucidate the role of this potential lipid metabolic mediator on MDSCs function in the tumor microenvironment.

\section{PI3K/AKT/mTOR}

Phosphoinositide-3-Kinase (PI3K) signaling performs an important role in regulating cellular functions and coordinate processes such as protein synthesis, glucose homeostasis, cellular metabolism, cell growth, migration, and survival (91). PI3K catalyzes the phosphorylation of phosphatidylinositol in the plasma membrane by adding a phosphate moiety to the $3^{\prime} \mathrm{OH}$ on the lipid (92). Several scientists investigating the etiology of cancer at the molecular level have intensely studied this pathway due to its frequent alteration in cancer (93). PI3K has been reported to regulate physiological activities in neutrophils $(94,95)$. In aging mice, bone marrow and secondary lymphoid organs accumulate a substantial level of MDSCs, which may be associated with altered PI3K/AKT signaling pathway. The molecular mechanism enhancing the suppressive activity of MDSCs revealed an upregulation in iNOS activity and inhibition of T-cell activation. This leads to an alteration in the immune system and supports immune senescence (96). These observations made PI3K signaling pathway a novel target for new cancer therapy (97) and we consider its signaling may be a potential modulator of lipid accumulation in MDSCs to enhance its suppressive activity on T-cells proliferation.

Phosphatase and tensin (PTEN) and 5-inositol phosphatase (SHIP) are negative regulators of the PI3K/AKT signaling pathway (Figure 3) regulating phosphoinositide metabolism in immune cells (98). SHIP suppresses cell growth and survival via the movement of cell membranes (shortly after stimulation of the extracellular compartment) leading to the conversion of phosphatidylinositol-3,4,5-triphosphate (PIP3) into phosphatidylinositol-3, 4- bisphosphate (PI3,4-P2), thus inhibiting PI3K (99). The MDSCs population can be increased through the downregulation of SHIP expression by cancer cells secreting factors such as GM-CSF, IL-6, and TGF- $\beta$. It was previously reported that increased MDSCs population in $\mathrm{SHIP}^{-/-}$tumor-bearing mice lymphoid compartment contributes to immunosuppressive allogenic $\mathrm{T}$-cell responses in vitro and in vivo (100). Hence, treatment strategies toward enhancing the activity of SHIP could mitigate the immunosuppressive effect of MDSCs and serve as therapeutic approaches in cancer (101).

The mammalian target of rapamycin (mTOR) is a major component of the PI3K/AKT pathway involved in cell proliferation and nutrient availability. It also controls the innate and adaptive immune response in multiple immune cells (102). Inhibition of mTOR signaling with rapamycin-induced the upregulation of arginase-1 and iNOS in MDSCs (103). Thus, enhancing MDSCs immunosuppressive activity and reduced T-cells proliferation. Constitutive initiation of Akt has been documented to promote lipid and sterol synthesis in addition to glycolysis $(104,105)$. Given that genetic manipulation of mTORC1 (either by deletion of TSC1 or TSC2 in fibroblast) activate downstream transcription factors involved in lipid biosynthesis (106), the signaling pathway via Akt-TSCmTORC1-S6K1-SREBP axis could be a possible pathway in MDSC. When mTORC1 is constitutively active, the transcription factor, SREBP is activated and drives the expression of sterol and fatty acid biosynthesis genes (106). The role of mTORC2 in lipid regulation unlike mTORC1 still remains unclear. Chen et al., recently highlighted another mTORC2 target, ATP citrate lyase (ACLY) in lipid metabolism. It converts citrate derived from the TCA cycle into acetyl CoA in the cytoplasm where it can be used for lipid biosynthesis. ACLY was identified as a target of mTORC2 in a breast cancer cell line; revealing that mTORC2 and not mTORC1 is necessary for the generation of acetyl CoA in an ACLY-catalyzed reaction (107). Inhibition of ACLY or mTORC2 activity altered mitochondrial function by reducing cell proliferation and tumor growth (108). Since mTORC2 can regulate lipid metabolism by limiting the activity of ACLY to generate the building blocks of lipids, targeting this signaling pathway could attenuate the immunosuppressive activities of MDSCs. 
Increased mRNA and protein synthesis resulting from the phosphorylation of S6K and 4EBP1 proteins via mTOR enhanced cell proliferation (109). Reports had shown the possible regulatory role of the $\mathrm{mTOR}$ pathway during inflammatory responses by an alteration in the activity of STAT3 and NF$\kappa \mathrm{B}$ in myeloid cells (110). Chen et al., showed the engagement of the MTOR signaling pathway in monocytes differentiation to TAM (111). The effect of mTOR signaling in promoting the expression of lipid and sterol genes when they are activated during myelopoiesis could contribute to lipid accumulation in MDSCs thereby enhancing their immunosuppressive function. Despite the progress made in studying this signaling pathway, how mTOR affects the immunosuppressive function of MDSCs is yet to be substantiated.

\section{STAT}

Members of the signal transducer and activator of transcription (STAT) protein family has been reported to regulate MDSCs functions by coordinating various activities (112). STAT3 signaling is crucial for the activation and expansion of MDSCs in several pathophysiological conditions (113) (Figure 3). STAT3 and STAT5 signaling induced by G-CSF and GMCSF, respectively, regulates the expression of proteins critical for expansion, differentiation and activation of MDSC (32). Recently, Al-Khami et al., demonstrated that the pharmacological blockage of STAT3 by FLLL32 or STAT5 by pimozide in BMderived MDSCs decreased the level of intracellular accumulated neutral lipids. More importantly, these inhibitors prevented the induction of arginase- 1 and iNOS, thereby abrogating the development of immunosuppressive functions of MDSCs. The effects of STAT3 and STAT5 inhibition suggest the role of lipids in driving the immunosuppressive function of MDSCs (25). Despite the available evidence, there is still a gap in understanding how STAT3/STAT5 signaling regulates lipid metabolism and immunosuppressive mechanisms in MDSCs.

Our group previously discovered that culturing mouse bone marrow-derived MDSCs in the presence of LA, elevated MDSCs proliferation while co-treatment with JS1-124 (STAT3 inhibitor) reversed this effect. MDSCs generated in vitro with or without JSI-124 or LA treatment was co-cultured with allogenic T-cells for 3 days to evaluate the influence of STAT3 on MDSCs suppressive activity by CFSE dilution. The proliferation of T-cell was elevated in the co-treated group compared to LA treated group (55). A marked decrease was observed in the suppressive ability of MDSCs generated in the presence of LA and JS1-124-treated cells (55). Furthermore, STAT3 inhibition or blockage in the expression of STAT3 in conditional knockout mice led to a decline in MDSCs number and improved T-cell response in tumor (114).

The transcriptional factor STAT5 can be activated by GM-CSF which has a key role in myelopoiesis and expansion of MDSCs (115). It was recently reported that GM-CSF in PMNs control the expression of FATP2 through the phosphorylation of STAT5 (26). Deletion of STAT5 in PMNs slowed tumor growth in comparison with the control mice. This was associated with a decreased expression of FATP2 in PMNs. Hence, STAT family could be another potential target for the immunosuppressive activity of MDSCs via fatty acid regulation.

\section{TIPE Family}

Tumor necrosis factor alpha-induced protein 8 like (TIPE or TNFAIP8L) family is a group of recently established regulators of tumorigenesis and immunity $(116,117)$. There are four homologous mammalian members of this family that have been identified including TIPE (the primary member of the family), TIPE1, TIPE2, and TIPE3 (118). TIPE and TIPE1 are ubiquitously expressed members, TIPE2 is found in the hematopoietic cells and TIPE3 expression is restricted to secretory epithelial tissues.

TIPE family was reported as the only defined transfer protein of second messenger molecules, phosphatidylinositol 4,5-bisphosphate (PIP2) and PIP3 (119, 120). Research revealed the involvement of TIPE family in the transport of phospholipids in and out of the plasma membrane via signaling of phosphoinositide to regulate PI3K (119) (Figure 3). Activation of PI3K can also stimulate the STAT3 pathway which is related to cancer and inflammation (121-123) as well as the NF- $\kappa \mathrm{B}$ signaling $(124,125)$. These signaling pathways play important roles in lipid metabolism and contribute to the immunosuppressive activities of $\operatorname{MDSCs}(25,55,100,101)$.

TIPE2 expression is most abundant in the hematopoietic cells (including MDSCs) and T-cells. Upon lipopolysaccharide (LPS) stimulation, nitric oxide production was increased due to loss of TIPE2 gene in macrophages (126). Likewise, it modulates macrophage response to oxidized low-density lipoproteins (oxLDL). Its deficiency in macrophage enhanced the stimulation of inflammatory cytokines which induced oxidative stress associated with p38, NF- $\mathrm{B}$, and JNK signaling (127). In relation to these findings, TIPE2 deficient bone marrow increased the formation of atherosclerosis in $\mathrm{Ldlr}^{-/-}$mice consuming ox-LDL and high-fat diet, suppressed TIPE2 mRNA expression (127). Exploring the crosstalk of lipid metabolism in MDSCs with TIPE2 could be another promising approach in cancer therapy.

\section{PGE2}

PGE2 is a pro-inflammatory molecule elicited by stromal, cancer, infiltrating myeloid cells, and associated with G-protein-coupling receptors (GPCRs). PGE2 is an important bioactive lipid and active product of cyclooxygenase 2 (COX-2). COX-2 catalyzes metabolic pathway involving the transformation of AA to an unstable intermediate PGG2, then to endoperoxide H2 (PGH2) and later into five primary prostanoids (TXA2, PGD2, PGE2, PGF2 $\alpha$, and PGI2) through cell-specific synthase (128). In MDSCs, PGE2 signals via the PGE2 receptor, E-prostanoid 4 (EP4) and upregulates arginase 1 activity in this cell, thereby enhancing its immunosuppressive role $(129,130)$.

Production of COX-2 increased MDSCs proliferation (Figure 3) correlated to an upregulation in the expression of arginase- 1 and iNOS in murine tumor-infiltrating leukocytes (131), thereby promoting tumor. Excess COX-2 stimulated the proliferation of malignant cells, thus compromised tumor immunity (132). PGE2/COX-2 signaling was involved in the differentiation of DC into MDSCs in an in vitro study (133). This 
impaired DC maturation and its antigen presentation ability, thus inhibiting MHC class II expression and T cell activation (134). Exploring COX-2 expression as a potential target could be a means to enhance immune surveillance and cancer therapy.

Studies on renal carcinoma cells (RCC) revealed the immunosuppressive influence of PGE2 on tumor cells through induction of arginase activity in MDSCs (135). This hindered T-cell activity in the tumor microenvironment resulting from the unavailability of L-arginine (136). Therefore, manipulation of PGE2 expression in MDSCs could enhance immunotherapy (137).

CXCR4 expression in differentiating MDSCs was elevated by the involvement of PGE2 in mice tumor cells $(138,139)$. Obermajer et al., established in human ovarian cancer that tumor-related PGE2, induced CXCL12 chemokine production and the expression of CXCR4 on MDSCs. The study also reported that PGE2 promotes COX2 expression in MDSCs. However, exposure of MDSCs from ovarian cancer cells to COX2 inhibitors decreased CXCR4 expression and sensitivity to recombinant CXCL12 (140). PGE2 possibly drives MDSCs accumulation by mobilizing chemokines to attract them from the circulation into the tumor microenvironment. COX-2 selective inhibitors and conventional non-steroidal anti-inflammatory drugs (NSAIDS) have previously been established to suppress immune evasion in tumors. It has been proposed that COX-2 inhibitors may stimulate type 1 immune responses by inhibiting MDSCs function (141).

A recent study reported that FATP2 promoted the suppressive role on PMN-MDSCs through the synthesis of PGE2, following exogenous uptake of AA (26). This suggests that regulation of the metabolic pathway involved in the transformation of AA to PGE2 via COX-2 may be a promising path in controlling lipid accumulation and attenuate the immunosuppressive function of MDSCs.

\section{CONCLUSIONS}

Metabolic alteration in cancerous cells has long been reported, however, a salient question yet to be fully investigated is the metabolic fate of tumor-associated immune cells. A better understanding of immunosuppression from a

\section{REFERENCES}

1. Bennett JA, Rao VS, Mitchell MS. Systemic bacillus Calmette-Guerin (BCG) activates natural suppressor cells. Proc. Natl. Acad. Sci USA. (1978) 75:51424. doi: 10.1073/pnas.75.10.5142

2. He YM, Li X, Perego M, Nefedova Y, Kossenkov AV, Jensen EA, et al. Transitory presence of myeloid-derived suppressor cells in neonates is critical for control of inflammation. Nat Med. (2018) 24:224-31. doi: $10.1038 / \mathrm{nm} .4467$

3. Gabrilovich DI, Bronte V, Chen S-H, Colombo MP, Ochoa A, OstrandRosenberg S, et al. The terminology issue for myeloid-derived suppressor cells. Cancer Res. (2007) 67:425. doi: 10.1158/0008-5472.CAN-06-3037

4. Bronte V, Brandau S, Chen SH, Colombo MP, Frey AB, Greten $\mathrm{TF}$, et al. Recommendations for myeloid-derived suppressor cell metabolic perspective may enhance the identification of new immunotherapeutic targets (142). Lipid metabolic reprogramming of MDSCs is a major contributing factor to its altered phenotype and co-opted immunosuppressive function. In MDSCs, the factors regulating the shift from glycolysis to FAO-OXPHOS in the tumor milieu and the molecular or transcriptional networks controlling its immunosuppressive role have not been fully explored. Understanding the precise roles of different forms of lipids in the tumor microenvironment is challenging. More research focus on elucidating lipid metabolism in MDSCs may enhance the development of therapies to treat cancer in the clinic.

\section{AUTHOR CONTRIBUTIONS}

DY, AA, and XW developed the study and wrote the paper. MX, LA, GZ, and YC contributed to the critical suggestion.

\section{FUNDING}

This work was supported by the National Natural Science Foundation of China (Grants 81501356 and 81373112), the Shenzhen Basic Science Research Project (Grants JCYJ20160229201353324, JCYJ20170413153158716, and JCYJ20170818164619194), Nanshan pilot team project (LHTD20160004), Start-up funding (CYZZ20180307154657923), the fourth talents project of Guangdong province (2014-1), the special funds for major science and technology of Guangdong province (2013A022100037), Guangdong Provincial Research Award for Thousand Talents Program Scholars, and Shenzhen special funds for industry of the future [Development and Reform Commission in Shenzhen (2015) Grant 971].

\section{ACKNOWLEDGMENTS}

We sincerely appreciate the critical suggestion and constructive criticisms received from Mrs. Funmilayo O. Adeshakin and Dr. Oluwarotimi. W. Samuel of Shenzhen Institute of Advanced Technology, Chinese Academy of Sciences during the preparation of this manuscript. 
8. Li M, Zhu D, Tian J, Wang S. Roles of myeloid-derived suppressor cell subpopulations in autoimmune arthritis. Front Immunol. (2018) 9:2849. doi: 10.3389/fimmu.2018.02849

9. Marvel D, Gabrilovich DI. Myeloid-derived suppressor cells in the tumor microenvironment: expect the unexpected. J Clin Invest. (2015) 125:3356-64. doi: 10.1172/JCI80005

10. Peranzoni E, Zilio S, Marigo I, Dolcetti L, Zanovello P, Mandruzzato S, et al. Myeloid-derived suppressor cell heterogeneity and subset definition. Curr Opin Immunol. (2010) 22:238-44. doi: 10.1016/j.coi.2010.01.021

11. Youn JI, Nagaraj S, Collazo M, Gabrilovich DI. Subsets of myeloid-derived suppressor cells in tumor-bearing mice. J Immunol. (2008) 181:5791-802. doi: 10.4049/jimmunol.181.8.5791

12. Youn JI, Gabrilovich DI. The biology of myeloid-derived suppressor cells: the blessing and the curse of morphological and functional heterogeneity. Eur J Immunol. (2010) 40:2969-75. doi: 10.1002/eji.201040895.

13. Dumitru CA, Moses K, Trellakis S, Lang S, Brandau S. Neutrophils and granulocytic myeloid-derived suppressor cells: immunophenotyping, cell biology and clinical relevance in human oncology. Cancer Immunol Immunother. (2012) 61:1155-67. doi: 10.1007/s00262-012-1294-5

14. Solito S, Marigo I, Pinton L, Damuzzo V, Mandruzzato S, Bronte V. Myeloidderived suppressor cell heterogeneity in human cancers. Ann N Y Acad Sci. (2014) 1319:47-65. doi: 10.1111/nyas.12469

15. Mohamed E, Al-Khami AA, Rodriguez PC. The cellular metabolic landscape in the tumor milieu regulates the activity of myeloid infiltrates. Cell $\mathrm{Mol}$ Immunol. (2018) 15:421. doi: 10.1038/s41423-018-0001-7

16. Porta C, Sica A, Riboldi E. Tumor-associated myeloid cells: new understandings on their metabolic regulation and their influence in cancer immunotherapy. FEBS J. (2018) 285:717-33. doi: 10.1111/febs.14288

17. Olenchock BA, Rathmell JC, Vander Heiden MG. Biochemical underpinnings of immune cell metabolic phenotypes. Immunity. (2017) 46:703-13. doi: 10.1016/j.immuni.2017.04.013

18. Van den Bossche J, O'Neill LA, Menon D. Macrophage immunometabolism: where are we (going)? Trends Immunol. (2017) 38:395-406. doi: 10.1016/j.it.2017.03.001

19. Bantug GR, Galluzzi L, Kroemer G, Hess C. The spectrum of T cell metabolism in health and disease. Nat Rev Immunol. (2018) 18:19-34. doi: 10.1038/nri.2017.99

20. Davies LC, Rice CM, McVicar DW, Weiss JM. Diversity and environmental adaptation of phagocytic cell metabolism. J Leukoc Biol. (2018) 105:37-48. doi: 10.1002/JLB.4RI0518-195R

21. Den Brok MH, Raaijmakers TK, Collado-Camps E, Adema GJ. Lipid droplets as immune modulators in myeloid cells. Trends Immunol. (2018) 39:380-92. doi: 10.1016/j.it.2018.01.012

22. Al-Khami AA, Rodriguez PC, Ochoa AC. Metabolic reprogramming of myeloid-derived suppressor cells (MDSC) in cancer. Oncoimmunology. (2016) 5:e1200771. doi: 10.1080/2162402X.2016.1200771

23. Clements VK, Long T, Long R, Figley C, Smith D, Ostrand-Rosenberg S. Frontline science: high fat diet and leptin promote tumor progression by inducing myeloid-derived suppressor cells. J Leukoc Biol. (2018) 103:395407. doi: 10.1002/JLB.4HI0517-210R

24. Veglia F, Tyurin V, Kagan V, Gabrilovich D. Oxidized lipids contribute to the suppression function of myeloid derived suppressor cells in cancer. In: Proceedings of the 106th Annual Meeting of the American Association for Cancer Research. Philadelphia, PA: AACR (2015). doi: 10.1158/1538-7445.AM2015-467

25. Al-Khami AA, Zheng L, Del Valle L, Hossain F, Wyczechowska D, Zabaleta J, et al. Exogenous lipid uptake induces metabolic and functional reprogramming of tumor-associated myeloid-derived suppressor cells. Oncoimmunology. (2017) 6:e1344804. doi: 10.1080/2162402X.2017.13 44804

26. Veglia F, Tyurin VA, Blasi M, De Leo A, Kossenkov AV, Donthireddy L, et al. Fatty acid transport protein 2 reprograms neutrophils in cancer. Nature. (2019) 569:73-8. doi: 10.1038/s41586-019-1118-2

27. Hossain F, Al-Khami AA, Wyczechowska D, Hernandez C, Zheng $\mathrm{L}$, Reiss $\mathrm{K}$, et al. Inhibition of fatty acid oxidation modulates immunosuppressive functions of myeloid-derived suppressor cells and enhances cancer therapies. Cancer Immunol Res. (2015) 3:1236-47. doi: 10.1158/2326-6066.CIR-15-0036
28. Alrob OA, Lopaschuk GD. Role of CoA and acetyl-CoA in regulating cardiac fatty acid and glucose oxidation. Biochem Soc T. (2014) 42:1043-51. doi: 10.1042/BST20140094

29. Lochner M, Berod L, Sparwasser T. Fatty acid metabolism in the regulation of $\mathrm{T}$ cell function. Trends Immunol. (2015) 36:81-91. doi: $10.1016 /$ j.it.2014.12.005

30. Ganeshan K, Chawla A. Metabolic regulation of immune responses. Annu Rev Immunol. (2014) 32:609-34. doi: 10.1146/annurev-immunol-032713-120236

31. O'Neill LA, Kishton RJ, Rathmell J. A guide to immunometabolism for immunologists. Nat Rev Immunol. (2016) 16:553-65. doi: $10.1038 /$ nri.2016.70

32. Gabrilovich DI, Ostrand-Rosenberg S, Bronte V. Coordinated regulation of myeloid cells by tumours. Nat Rev Immunol. (2012) 12:253-68. doi: $10.1038 /$ nri3175

33. Rodriguez PC, Quiceno DG, Zabaleta J, Ortiz B, Zea AH, Piazuelo MB, et al. Arginase I production in the tumor microenvironment by mature myeloid cells inhibits T-cell receptor expression and antigen-specific T-cell responses. Cancer Res. (2004) 64:5839-49. doi: 10.1158/0008-5472.CAN-04-0465

34. Srivastava MK, Sinha P, Clements VK, Rodriguez P, OstrandRosenberg S. Myeloid-derived suppressor cells inhibit T-cell activation by depleting cystine and cysteine. Cancer Res. (2010) 70:68-77. doi: 10.1158/0008-5472.CAN-09-2587

35. Munn DH, Shafizadeh E, Attwood JT, Bondarev I, Pashine A, Mellor AL. Inhibition of $\mathrm{T}$ cell proliferation by macrophage tryptophan catabolism. $J$ Exp Med. (1999) 189:1363-72. doi: 10.1084/jem.189.9.1363

36. Martinez FO, Gordon S, Locati M, Mantovani A. Transcriptional profiling of the human monocyte-to-macrophage differentiation and polarization: new molecules and patterns of gene expression. J Immunol. (2006) 177:7303-11. doi: 10.4049/jimmunol.177.10.7303

37. Saxena V, Ondr JK, Magnusen AF, Munn DH, Katz JD. The countervailing actions of myeloid and plasmacytoid dendritic cells control autoimmune diabetes in the nonobese diabetic mouse. J Immunol. (2007) 179:5041-53. doi: 10.4049/jimmunol.179.8.5041

38. Grohmann U, Bronte V. Control of immune response by amino acid metabolism. Immunol Rev. (2010) 236:243-64. doi: 10.1111/j.1600-065X.2010.00915.x

39. Sica A, Strauss L. Energy metabolism drives myeloid-derived suppressor cell differ -entiation and functions in pathology. J Leukoc Biol. (2017) 102:32534. doi: 10.1189/jlb.4MR1116-476R

40. Jian SL, Chen WW, Su YC, Su YW, Chuang TH, Hsu SC, et al. Glycolysis regulates the expansion of myeloid-derived suppressor cells in tumorbearing hosts through prevention of ROS-mediated apoptosis. Cell Death Dis. (2017) 8:e2779. doi: 10.1038/cddis.2017.192

41. Cai TT, Ye SB, Liu YN, He J, Chen QY, Mai HQ, et al. LMP1mediated glycolysis induces myeloid-derived suppressor cell expansion in nasopharyngeal carcinoma. PLoS Pathog. (2017) 13:e1006503. doi: 10.1371/journal.ppat.1006503

42. Lo AKF, Lung RWM, Dawson CW, Young LS, Ko CW, Yeung $\mathrm{WW}$, et al. Activation of sterol regulatory element-binding protein 1 (SREBP1)-mediated lipogenesis by the Epstein-Barr virus-encoded latent membrane protein 1 (LMP1) promotes cell proliferation and progression of nasopharyngeal carcinoma. J Pathol. (2018) 246:180-90. doi: $10.1002 /$ path. 5130

43. Li W, Tanikawa T, Kryczek I, Xia H, Li G, Wu K, et al. Aerobic glycolysis controls myeloid-derived suppressor cells and tumor immunity via a specific CEBPB isoform in triple-negative breast cancer. Cell Metab. (2018) 28:87103.e6. doi: 10.1016/j.cmet.2018.04.022

44. Husain Z, Huang Y, Seth P, Sukhatme VP. Tumor-derived lactate modifies antitumor immune response: effect on myeloid-derived suppressor cells and NK cells. J Immunol. (2013) 191:1486-95. doi: 10.4049/jimmunol.1202702

45. Hammami I, Chen J, Murschel F, Bronte V, De Crescenzo G, Jolicoeur M. Immunosuppressive activity enhances central carbon metabolism and bioenergetics in myeloid-derived suppressor cells in vitro models. BMC Cell Biol. (2012) 13:18. doi: 10.1186/1471-2121-13-18

46. Valvona CJ, Fillmore HL, Nunn PB, Pilkington GJ. The regulation and function of lactate dehydrogenase a: therapeutic potential in brain tumor. Brain Pathol. (2016) 26:3-17. doi: 10.1111/bpa.12299 
47. Biswas SK. Metabolic reprogramming of immune cells in cancer progression. Immunity. (2015) 43:435-49. doi: 10.1016/j.immuni.2015.09.001

48. Blagih J, Jones RG. Polarizing macrophages through reprogramming of glucose metabolism. Cell Metab. (2012) 15:793-5. doi: 10.1016/j.cmet.2012.05.008

49. Mantovani A, Sica A. Macrophages, innate immunity and cancer: balance, tolerance, and diversity. Curr Opin Immunol. (2010) 22:231-7. doi: 10.1016/j.coi.2010.01.009

50. Yang WC, Ma G, Chen SH, Pan PY. Polarization and reprogramming of myeloid-derived suppressor cells. J Mol Cell Biol. (2013) 5:207-9. doi: $10.1093 / \mathrm{jmcb} / \mathrm{mjt} 009$

51. Herber DL, Cao W, Nefedova Y, Novitskiy SV, Nagaraj S, Tyurin VA, et al. Lipid accumulation and dendritic cell dysfunction in cancer. Nat Med. (2010) 16:880-6. doi: 10.1038/nm.2172

52. Cao W, Ramakrishnan R, Tuyrin VA, Veglia F, Condamine T, Amoscato A, et al. Oxidized lipids block antigen cross-presentation by dendritic cells in cancer. J Immunol. (2014) 192:2920-31. doi: 10.4049/jimmunol.1302801

53. Cao W, Gabrilovich D. Contribution of fatty acid accumulation to myeloidderived suppressor cell function in cancer. In: Proceedings of the 102nd Annual Meeting of the American Association for Cancer Research. Orlando, FL; Philadelphia, PA: AACR (2011). doi: 10.1158/1538-7445.AM2011-3649

54. Veglia F, Tyurin VA, Kagan VE, Gabrilovich D. Lipids and suppressive functions of MDSC in cancer. In: Proceedings of the Annual Meeting 2018. Chicago, IL; Philadelphia, PA: AACR (2018).

55. Yan D, Yang Q, Shi M, Zhong L, Wu C, Meng T, et al. Polyunsaturated fatty acids promote the expansion of myeloid-derived suppressor cells by activating the JAK/STAT3 pathway. Eur J Immunol. (2013) 43:2943-55. doi: $10.1002 /$ eji.201343472

56. Rose DP. Effects of dietary fatty acids on breast and prostate cancers: evidence from in vitro experiments and animal studies. Am J Clin Nutr. (1997) 66:1513S-22. doi: 10.1093/ajcn/66.6.1513S

57. Wu H, Weidinger C, Schmidt F, Keye J, Friedrich M, Yerinde C, et al. Oleate but not stearate induces the regulatory phenotype of myeloid suppressor cells. Sci Rep. (2017) 7:7498. doi: 10.1038/s41598-017-07685-9

58. Al-Khami AA, Rodriguez PC, Ochoa AC. Energy metabolic pathways control the fate and function of myeloid immune cells. J Leukoc Biol. (2017) 102:36980. doi: 10.1189/jlb.1VMR1216-535R

59. Hong C, Tontonoz P. Liver $\mathrm{X}$ receptors in lipid metabolism: opportunities for drug discovery. Nat Rev Drug Discov. (2014) 13:433-44. doi: $10.1038 / \operatorname{nrd} 4280$

60. Evans RM, Mangelsdorf DJ. Nuclear receptors, RXR, and the big bang. Cell. (2014) 157:255-66. doi: 10.1016/j.cell.2014.03.012

61. Tavazoie MF, Pollack I, Tanqueco R, Ostendorf BN, Reis BS, Gonsalves FC, et al. LXR/ApoE activation restricts innate immune suppression in cancer. Cell. (2018) 172:825-40.e18. doi: 10.1016/j.cell.2017.12.026

62. Ma X, Bi E, Huang C, Lu Y, Xue G, Guo X, et al. Cholesterol negatively regulates IL-9-producing $\mathrm{CD} 8(+) \mathrm{T}$ cell differentiation and antitumor activity. J Exp Med. (2018) 215:1555-69. doi: 10.1084/jem.20171576

63. Lu Y, Hong S, Li H, Park J, Hong B, Wang L, et al. Th9 cells promote antitumor immune responses in vivo. J Clin Invest. (2012) 122:4160-71. doi: 10.1172/JCI65459

64. Lu Y, Hong B, Li H, Zheng Y, Zhang M, Wang S, et al. Tumor-specific IL9-producing CD8+ Tc9 cells are superior effector than type-I cytotoxic Tc1 cells for adoptive immunotherapy of cancers. Proc Natl Acad Sci USA. (2014) 111:2265-70. doi: 10.1073/pnas.1317431111

65. Schlapbach C, Gehad A, Yang C, Watanabe R, Guenova E, Teague JE, et al. Human TH9 cells are skin-tropic and have autocrine and paracrine proinflammatory capacity. Sci Transl Med. (2014) 6:219ra8. doi: $10.1126 /$ scitranslmed.3007828

66. Parrot T, Allard M, Oger R, Benlalam H, Raingeard de la Bletiere D, Coutolleau A, et al. IL-9 promotes the survival and function of human melanoma-infiltrating $\mathrm{CD} 4(+) \mathrm{CD} 8(+)$ double-positive T cells. Eur J Immunol. (2016) 46:1770-82. doi: 10.1002/eji.201546061

67. Laffitte BA, Repa JJ, Joseph SB, Wilpitz DC, Kast HR, Mangelsdorf DJ, et al. LXRs control lipid-inducible expression of the apolipoprotein E gene in macrophages and adipocytes. Proc Natl Acad Sci USA. (2001) 98:507-12. doi: $10.1073 /$ pnas. 021488798
68. Huang Y, Mahley RW. Apolipoprotein E: structure and function in lipid metabolism, neurobiology, and Alzheimer's diseases. Neurobiol Dis. (2014) 72(Pt A):3-12. doi: 10.1016/j.nbd.2014.08.025

69. El RA, Bard JM, Valin S, Huvelin JM, Nazih H. Macrophage apolipoprotein $\mathrm{E}$ and proliferation of MCF-7 breast cancer cells: role of LXR. Anticancer Res. (2013) 33:3783-9. doi : 10.1007/s11839-013-0432-4

70. Wahli W, Michalik L. PPARs at the crossroads of lipid signaling and inflammation. Trends Endocrinol Metab. (2012) 23:351-63. doi: $10.1016 /$ j.tem.2012.05.001

71. Song S, Attia RR, Connaughton S, Niesen MI, Ness GC, Elam MB, et al. Peroxisome proliferator activated receptor $\alpha(\mathrm{PPAR} \alpha)$ and PPAR gamma coactivator (PGC-1 $\alpha)$ induce carnitine palmitoyltransferase IA (CPT-1A) via independent gene elements. Mol Cell Endocrinol. (2010) 325:54-63. doi: 10.1016/j.mce.2010.05.019

72. Zhao T, Du H, Blum JS, Yan C. Critical role of PPAR $\gamma$ in myeloidderived suppressor cell-stimulated cancer cell proliferation and metastasis. Oncotarget. (2016) 7:1529-43. doi: 10.18632/oncotarget.6414.

73. La Cour Poulsen L, Siersbæk M, Mandrup S. PPARs: fatty acid sensors controlling metabolism. Semin Cell Dev Biol. (2012) 23:631-9. doi: 10.1016/j.semcdb.2012.01.003

74. Chakraborty K, Raundhal M, Chen BB, Morse C, Tyurina YY, Khare A, et al. The mito-DAMP cardiolipin blocks IL-10 production causing persistent inflammation during bacterial pneumonia. Nat Commun. (2017) 8:13944. doi: 10.1038/ncomms13944

75. Llovet JM, Villanueva A. Liver cancer: effect of HCV clearance with directacting antiviral agents on HCC. Nat Rev Gastroenterol Hepatol. (2016) 13:561-2. doi: 10.1038/nrgastro.2016.140

76. Brown ZJ, Fu Q, Ma C, Kruhlak M, Zhang H, Luo J, et al. Carnitine palmitoyltransferase gene upregulation by linoleic acid induces $\mathrm{CD} 4+\mathrm{T}$ cell apoptosis promoting HCC development. Cell Death Dis. (2018) 9:620. doi: 10.1038/s41419-018-0687-6

77. Zhang Y, Kurupati R, Liu L, Zhou XY, Zhang G, Hudaihed A, et al. Enhancing $\mathrm{CD} 8+\mathrm{T}$ cell fatty acid catabolism within a metabolically challenging tumor micro- environment increases the efficacy of melanoma immunotherapy. Cancer Cell. (2017) 32:377-91.e9. doi: 10.1016/j.ccell.2017.08.004

78. Galic S, Fullerton MD, Schertzer JD, Sikkema S, Marcinko K, Walkley CR, et al. Hematopoietic AMPK $\beta 1$ reduces mouse adipose tissue macrophage inflammation and insulin resistance in obesity. J Clin Invest. (2011) 121:4903-15. doi: 10.1172/JCI58577

79. De Veirman K, Menu E, Maes K, De Beule N, De Smedt E, Maes A, et al. Myeloid-derived suppresor cells induce multiple myeloma cell survival by activating the AMPK pathway. Cancer Lett. (2018) 442:233-41. doi: 10.1016/j.canlet.2018.11.002

80. Zhao C, Zhang Q, Yu T, Sun S, Wang W, Liu G. Hypoxia promotes drug resistance in osteosarcoma cells via activating AMP-activated protein kinase (AMPK) signaling. J Bone Oncol. (2016) 5:22-9. doi: 10.1016/j.jbo.2016.01.002

81. Zhao Y, Hu X, Liu Y, Dong S, Wen Z, He W, et al. ROS signaling under metabolic stress: cross-talk between AMPK and AKT pathway. Mol Cancer. (2017) 16:79. doi: 10.1186/s12943-017-0648-1

82. Chen X, Song M, Zhang B, Zhang Y. Reactive oxygen species regulate T cell immune response in the tumor microenvironment. Oxid Med Cell Longev. (2016) 2016:1580967. doi: 10.1155/2016/1580967

83. Corzo CA, Cotter MJ, Cheng P, Cheng F, Kusmartsev S, Sotomayor E, et al. Mechanism regulating reactive oxygen species in tumorinduced myeloid-derived suppressor cells. J Immunol. (2009) 182:5693-701. doi: 10.4049/jimmunol.0900092

84. Ohl K, Tenbrock K. Reactive oxygen species as regulators of MDSC-mediated immune suppression. Front Immunol. (2018) 9:2499.doi: 10.3389/fimmu.2018.02499

85. Pal S, Nandi M, Dey D, Ahammed S, Banerjee S, Santra A, et al. MyeloidDerived Suppressor Cells: key players mediating immunosuppression via induction of Regulatory T-cell by TGF $\beta$ and $\mathrm{IL}-10$ driven pathways in chronic HBV infection. J Hepatol. (2017) 66:S541-2. doi: 10.1016/S0168-8278(17)31490-3

86. Bah I, Kumbhare A, Nguyen L, McCall CE, El Gazzar M. IL-10 induces an immune repressor pathway in sepsis by promoting S100A9 nuclear 
localization and MDSC development. Cell Immunol. (2018) 332:32-8. doi: 10.1016/j.cellimm.2018.07.003

87. O'neill LA, Hardie DG. Metabolism of inflammation limited by AMPK and pseudo-starvation. Nature. (2013) 493:346-55. doi: 10.1038/nature11862

88. Trikha P, Plews RL, Stiff A, Gautam S, Hsu V, Abood D, et al. Targeting myeloid-derived suppressor cells using a novel adenosine monophosphateactivated protein kinase (AMPK) activator. Oncoimmunology. (2016) 5:e1214787. doi: 10.1080/2162402X.2016.1214787

89. Kim SH, Li M, Trousil S, Zhang Y, di Magliano MP, Swanson KD, et al. Phenformin inhibits myeloid-derived suppressor cells and enhances the antitumor activity of PD-1 blockade in melanoma. J Invest Dermatol. (2017) 137:1740-8. doi: 10.1016/j.jid.2017.03.033

90. Rong Y, Yuan CH, Qu Z, Zhou H, Guan Q, Yang N, et al. Doxorubicin resistant cancer cells activate myeloid-derived suppressor cells by releasing PGE 2. Sci Rep. (2016) 6:23824. doi: 10.1038/srep23824

91. Xie Y, Shi X, Sheng K, Han G, Li W, Zhao Q, et al. PI3K/Akt signaling transduction pathway, erythropoiesis and glycolysis in hypoxia. Mol Med Rep. (2019) 19:783-91. doi: 10.3892/mmr.2018.9713

92. Engelman JA, Luo J, Cantley LC. The evolution of phosphatidylinositol 3kinases as regulators of growth and metabolism. Nat Rev Genet. (2006) 7:606-19. doi: $10.1038 / \operatorname{nrg} 1879$

93. Hanahan D, Weinberg RA. Hallmarks of cancer: the next generation. Cell. (2011) 144:646-74. doi: 10.1016/j.cell.2011.02.013

94. Lindemans C, Coffer P. Regulation of granulocyte apoptosis by phosphatidylinositol 3-kinase. Biochem Soc Trans. (2004) 32:480-4. doi: 10.1042/BST0320480

95. Yang KY, Arcaroli J, Kupfner J, Pitts TM, Park JS, Strasshiem D, et al. Involvement of phosphatidylinositol 3-kinase $\gamma$ in neutrophil apoptosis. Cell Signal. (2003) 15:225-33. doi: 10.1016/S0898-6568(02)00063-3

96. Enioutina EY, Bareyan D, Daynes RA. A role for immature myeloid cells in immune senescence. J Immunol. (2011) 186:697-707. doi: $10.4049 /$ jimmunol.1002987

97. Lien EC, Dibble CC, Toker A. PI3K signaling in cancer: beyond AKT. Curr Opin Cell Biol. (2017) 45:62-71. doi: 10.1016/j.ceb.2017.02.007

98. Cully M, You H, Levine AJ, Mak TW. Beyond PTEN mutations: the PI3K pathway as an integrator of multiple inputs during tumorigenesis. Nat Rev Cancer. (2006) 6:184-92. doi: 10.1038/nrc1819

99. Damen JE, Ware MD, Kalesnikoff J, Hughes MR, Krystal G. SHIP's Cterminus is essential for its hydrolysis of PIP3 and inhibition of mast cell degranulation. Blood. (2001) 97:1343-51. doi: 10.1182/blood.V97.5.1343

100. Ghansah T, Paraiso KH, Highfill S, Desponts C, May S, McIntosh JK, et al. Expansion of myeloid suppressor cells in SHIP-deficient mice represses allogeneic T cell responses. J Immunol. (2004) 173:7324-30. doi: 10.4049/jimmunol.173.12.7324

101. Ghansah T. A novel strategy for modulation of MDSC to enhance cancer immunotherapy. Oncoimmunology. (2012) 1:984-5. doi: 10.4161/onci.20201

102. Linke M, Fritsch SD, Sukhbaatar N, Hengstschläger M, Weichhart T. mTORC1 and mTORC2 as regulators of cell metabolism in immunity. FEBS Lett. (2017) 591:3089-103. doi: 10.1002/1873-3468.12711

103. Zhang C, Wang S, Li J, Zhang W, Zheng L, Yang C, et al. The mTOR signal regulates myeloid-derived suppressor cells differentiation and immunosuppressive function in acute kidney injury. Cell Death Dis. (2017) 8:e2695. doi: 10.1038/cddis.2017.86

104. Majumder PK, Febbo PG, Bikoff R, Berger R, Xue Q, McMahon LM, et al. mTOR inhibition reverses Akt-dependent prostate intraepithelial neoplasia through regulation of apoptotic and HIF-1-dependent pathways. Nat Med. (2004) 10:594-601. doi: 10.1038/nm1052

105. Porstmann T, Griffiths B, Chung YL, Delpuech O, Griffiths JR, Downward J, et al. $\mathrm{PKB} /$ Akt induces transcription of enzymes involved in cholesterol and fatty acid biosynthesis via activation of SREBP. Oncogene. (2005) 24:6465-81. doi: 10.1038/sj.onc. 1208802

106. Düvel K, Yecies JL, Menon S, Raman P, Lipovsky AI, Souza AL, et al. Activation of a metabolic gene regulatory network downstream of mTOR complex 1. Mol Cell. (2010) 39:171-83. doi: 10.1016/j.molcel.2010.06.022

107. Chen Y, Qian J, He Q, Zhao H, Toral-Barza L, Shi C, et al. mTOR complex2 stimulates acetyl-CoA and de novo lipogenesis through ATP citrate lyase in HER2/PIK3CA-hyperactive breast cancer. Oncotarget. (2016) 7:25224-40. doi: $10.18632 /$ oncotarget.8279
108. Fritsch SD, Weichhart T. Effects of interferons and viruses on metabolism. Front Immunol. (2016) 7:630. doi: 10.3389/fimmu.2016.00630

109. Ballou LM, Lin RZ. Rapamycin and mTOR kinase inhibitors. J Chem Biol. (2008) 1:27-36. doi: 10.1007/s12154-008-0003-5

110. Weichhart T, Costantino G, Poglitsch M, Rosner M, Zeyda M, Stuhlmeier KM, et al. The TSC-mTOR signaling pathway regulates the innate inflammatory response. Immunity. (2008) 29:565-77. doi: 10.1016/j.immuni.2008.08.012

111. Chen W, Ma T, Shen XN, Xia XF, Xu GD, Bai XL, et al. Macrophage-induced tumor angiogenesis is regulated by the TSC2-mTOR pathway. Cancer Res. (2012) 72:1363-72. doi: 10.1158/0008-5472

112. Pan T, Zhong L, Wu S, Cao Y, Yang Q, Cai Z, et al. 17ß-Oestradiol enhances the expansion and activation of myeloid-derived suppressor cells via signal transducer and activator of transcription (STAT) - 3 signalling in human pregnancy. Clin Exp Immunol. (2016) 185:86-97. doi: 10.1111/cei.12790

113. Ma J, Xu H, Wang S. Immunosuppressive role of myeloid-derived suppressor cells and therapeutic targeting in lung cancer. J Immunol Res. (2018) 2018:6319649. doi: 10.1155/2018/6319649

114. Nefedova Y, Nagaraj S, Rosenbauer A, Muro-Cacho C, Sebti SM, Gabrilovich DI. Regulation of dendritic cell differentiation and antitumor immune response in cancer by pharmacologic-selective inhibition of the janus-activated kinase 2/signal transducers and activators of transcription 3 pathway. Cancer Res. (2005) 65:9525-35. doi: 10.1158/0008-5472.CAN-05-0529

115. Casbon AJ, Reynaud D, Park C, Khuc E, Gan DD, Schepers K, et al. Invasive breast cancer reprograms early myeloid differentiation in the bone marrow to generate immunosuppressive neutrophils. Proc Natl Acad Sci USA. (2015) 112:E566-75. doi: 10.1073/pnas.1424927112

116. Sun H, Gong S, Carmody RJ, Hilliard A, Li L, Sun J, et al. TIPE2, a negative regulator of innate and adaptive immunity that maintains immune homeostasis. Cell. (2008) 133:415-26. doi: 10.1016/j.cell.2008.03.026

117. Kumar D, Gokhale P, Broustas C, Chakravarty D, Ahmad I, Kasid U. Expression of SCC-S2, an antiapoptotic molecule, correlates with enhanced proliferation and tumorigenicity of MDA-MB 435 cells. Oncogene. (2004) 23:612-6. doi: 10.1038/sj.onc.1207123

118. Goldsmith JR, Chen YH. Regulation of inflammation and tumorigenesis by the TIPE family of phospholipid transfer proteins. Cell Mol Immunol. (2017) 14:482-7. doi: 10.1038/cmi.2017.127

119. Fayngerts SA, Wu J, Oxley CL, Liu X, Vourekas A, Cathopoulis T, et al. TIPE3 is the transfer protein of lipid second messengers that promote cancer. Cancer Cell. (2014) 26:465-78. doi: 10.1016/j.ccr.2014.07.025

120. Fayngerts SA, Wang Z, Zamani A, Sun H, Boggs AE, Porturas $\mathrm{TP}$, et al. Direction of leukocyte polarization and migration by the phosphoinositide-transfer protein TIPE2. Nat Immunol. (2017) 18:1353-60. doi: 10.1038/ni.3866.

121. Hart JR, Liao L, Yates JR, Vogt PK. Essential role of Stat3 in PI3K-induced oncogenic transformation. Proc Natl Acad Sci USA. (2011) 108:13247-52. doi: $10.1073 /$ pnas. 1110486108

122. Yu H, Lee H, Herrmann A, Buettner R, Jove R. Revisiting STAT3 signalling in cancer: new and unexpected biological functions. Nat Rev Cancer. (2014) 14:736-46. doi: 10.1038/nrc3818

123. Yan DH, Wang JH, Wan XC. TIPE2 is a novel direct target of STAT3 in MDSC and inhibition of its expression on MDSC enhanced T cell activation in tumor. J Immunol. (2017) 198:205.

124. Fan Y, Mao R, Yang J. NF-kB and STAT3 signaling pathways collaboratively link inflammation to cancer. Protein Cell. (2013) 4:176-85. doi: 10.1007/s13238-013-2084-3

125. Lian K, Ma C, Hao C, Li Y, Zhang N, Chen YH, et al. TIPE3 protein promotes breast cancer metastasis through activating AKT and NF- $\mathrm{KB}$ signaling pathways. Oncotarget. (2017) 8:48889-904. doi: 10.18632/oncotarget.1 6522

126. Lou Y, Zhang G, Geng M, Zhang W, Cui J, Liu S. TIPE2 negatively regulates inflammation by switching arginine metabolism from nitric oxide synthase to arginase. PLoS ONE. (2014) 9:e96508. doi: 10.1371/journal.pone.0096508

127. Lou Y, Liu S, Zhang C, Zhang G, Li J, Ni M, et al. Enhanced atherosclerosis in TIPE2-deficient mice is associated with increased macrophage responses to oxidized low-density lipoprotein. J Immunol. (2013) 191:4849-57. doi: 10.4049/jimmunol.1300053 
128. Trikha P, Carson III WE. Signaling pathways involved in MDSC regulation. Biochim Biophys Acta. (2014) 1846:55-65. doi: 10.1016/j.bbcan.2014.04.003

129. Rodriguez PC, Hernandez CP, Quiceno D, Dubinett SM, Zabaleta J, Ochoa JB, et al. Arginase I in myeloid suppressor cells is induced by COX-2 in lung carcinoma. J Exp Med. (2005) 202:931-9. doi: 10.1084/jem.20050715

130. Zhang Y, Liu Q, Zhang M, Yu Y, Liu X, Cao X. Fas signal promotes lung cancer growth by recruiting myeloid-derived suppressor cells via cancer cell-derived PGE2. J Immunol. (2009) 182:3801-8. doi: 10.4049/jimmunol.0801548

131. Donkor MK, Lahue E, Hoke TA, Shafer LR, Coskun U, Solheim JC, et al. Mammary tumor heterogeneity in the expansion of myeloidderived suppressor cells. Int Immunopharmacol. (2009) 9:937-48. doi: 10.1016/j.intimp.2009.03.021

132. Liu B, Qu L, Yan S. Cyclooxygenase-2 promotes tumor growth and suppresses tumor immunity. Cancer Cell Int. (2015) 15:106. doi: 10.1186/s12935-015-0260-7

133. Obermajer N, Muthuswamy R, Lesnock J, Edwards RP, Kalinski P. Positive feedback between PGE2 and COX2 redirects the differentiation of human dendritic cells toward stable myeloid-derived suppressor cells. Blood. (2011) 118:5498-505. doi: 10.1182/blood-2011-07-36 5825

134. Harizi H, Grosset C, Gualde N. Prostaglandin E2 modulates dendritic cell function via EP2 and EP4 receptor subtypes. J Leukoc Biol. (2003) 73:756-63. doi: $10.1189 / \mathrm{jlb} .1002483$

135. Smyth GP, Stapleton PP, Barden CB, Mestre JR, Freeman TA, Duff MD, et al. Renal cell carcinoma induces prostaglandin E2 and T-helper type 2 cytokine production in peripheral blood mononuclear cells. Ann Surg Oncol. (2003) 10:455-62. doi: 10.1245/ASO.2003.06.036

136. Tate DJ, Vonderhaar DJ, Caldas YA, Metoyer T, Patterson JR, Aviles DH, et al. Effect of arginase II on L-arginine depletion and cell growth in murine cell lines of renal cell carcinoma. J Hematol Oncol. (2008) 1:14. doi: $10.1186 / 1756-8722-1-14$
137. Sun L, Suo C, Li ST, Zhang H, Gao P. Metabolic reprogramming for cancer cells and their microenvironment: beyond the Warburg Effect. Biochim Biophys Acta. (2018) 1870:51-66. doi: 10.1016/j.bbcan.2018.06.005

138. Eruslanov E, Neuberger M, Daurkin I, Perrin GQ, Algood C, Dahm P, et al. Circulating and tumor-infiltrating myeloid cell subsets in patients with bladder cancer. Int J Cancer. (2012) 130:1109-19. doi: 10.1002/ijc.26123

139. Kusmartsev S, Eruslanov E, Kübler H, Tseng T, Sakai Y, Su Z, et al. Oxidative stress regulates expression of VEGFR1 in myeloid cells: link to tumorinduced immune suppression in renal cell carcinoma. J Immunol. (2008) 181:346-53. doi: 10.4049/jimmunol.181.1.346

140. Obermajer N, Muthuswamy R, Odunsi K, Edwards RP, Kalinski P. PGE2-induced CXCL12 production and CXCR4 expression controls the accumulation of human MDSCs in ovarian cancer environment. Cancer Res. (2011) 71:7463-70. doi: 10.1158/0008-5472.CAN-11-2449

141. Jing H, Vassiliou E, Ganea D. Prostaglandin E2 inhibits production of the inflammatory chemokines CCL3 and CCL4 in dendritic cells. J Leukoc Biol. (2003) 74:868-79. doi: 10.1189/jlb.0303116

142. O'Sullivan D, Sanin DE, Pearce EJ, Pearce EL. Metabolic interventions in the immune response to cancer. Nat Rev Immunol. (2019) 19:324-35. doi: 10.1038/s41577-019-0140-9

Conflict of Interest Statement: The authors declare that the research was conducted in the absence of any commercial or financial relationships that could be construed as a potential conflict of interest.

Copyright $\odot 2019$ Yan, Adeshakin, Xu, Afolabi, Zhang, Chen and Wan. This is an open-access article distributed under the terms of the Creative Commons Attribution License (CC BY). The use, distribution or reproduction in other forums is permitted, provided the original author(s) and the copyright owner(s) are credited and that the original publication in this journal is cited, in accordance with accepted academic practice. No use, distribution or reproduction is permitted which does not comply with these terms. 